\title{
La restauración de la Puerta de Córdoba en Carmona: del proyecto a la obra
}

\author{
Antonio Tejedor Cabrera \\ Dr. Arquitecto
}

Como puerta urbana que servía para acceder a Carmona por el lado oriental, la Puerta de Córdoba ha desempeñado a lo largo de veinte siglos la misma función para la que fue construida, lo que unido a su privilegiada ubicación dominando el paisaje de la vega justifica el extraordinario valor cultural de esta arquitectura civil declarada Monumento Histórico en 1931.

Concebida en su origen romano como arco triunfal destinado a la propaganda de los atributos del imperio en un enclave paisajístico de extraordinaria potencia visual, la Puerta de Córdoba ocupa un lugar privilegiado en el perfil natural del escarpe de Car- mona. Hacia levante, la meseta sobre la que se asienta la ciudad permitía el control militar del territorio circundante; por aquí cruzaba la Via Augusta, la principal calzada del Valle del Guadalquivir, paso obligado de todas las comunicaciones entre Hispalis y Corduba.

La Puerta de Córdoba surge en época de Augusto (inicios del siglo I d.C.) entre dos afloramientos de alcor, justamente en el lugar en el que la topografía se hace más accesible por la presencia de una vaguada surgida en la cuenca natural de drenaje de una buena parte de la meseta. A ambos lados de este acceso se preservaron amplias franjas libres de edificación hasta los bordes del escarpe, a modo de zonas de seguridad en caso de asedio o invasión de la ciudad. Hasta las últimas décadas del siglo XX, estos espacios del entorno de la Puerta de Córdoba,

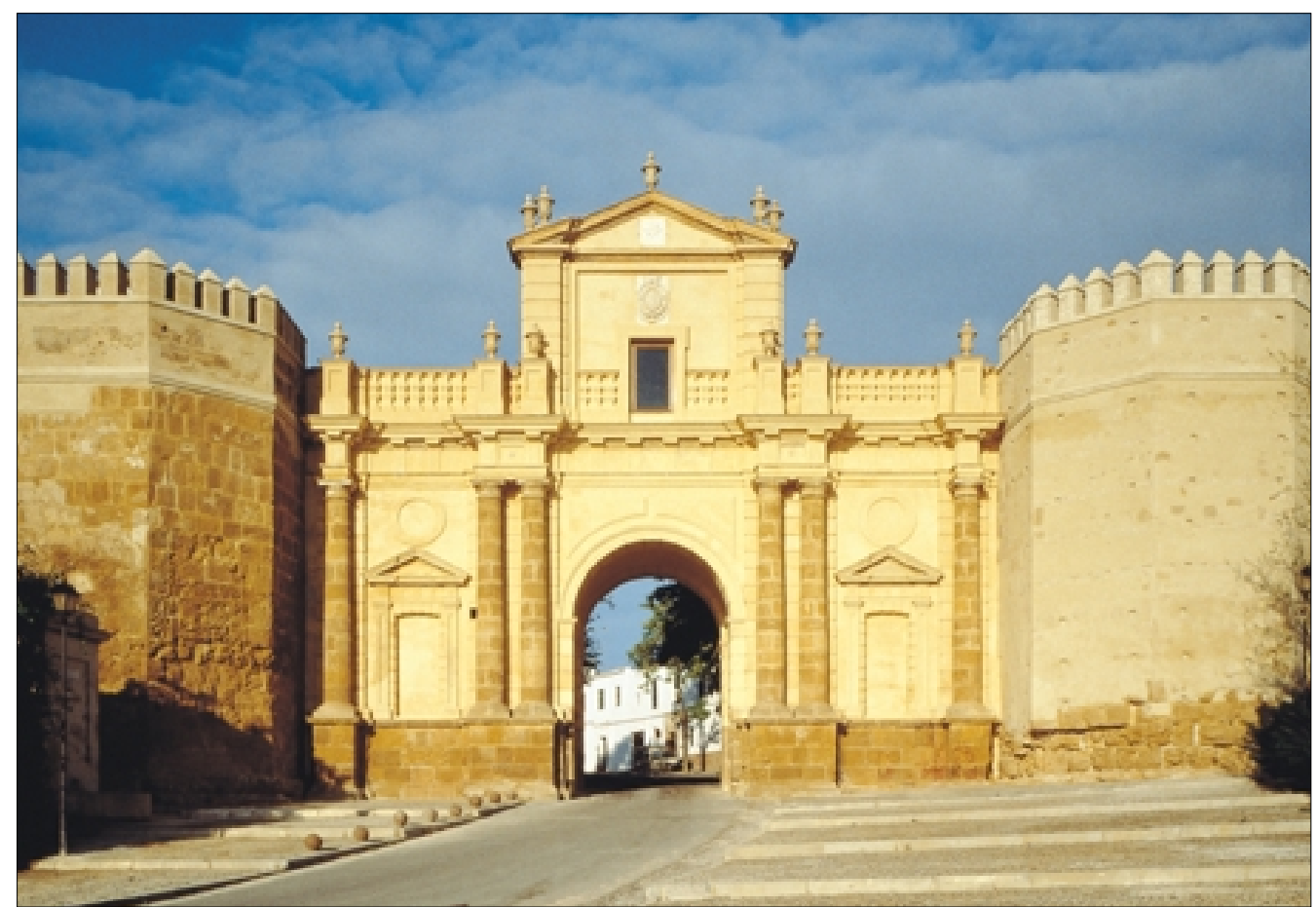


El proyecto de restauración se entendía como un instrumento destinado a hacer más palpables las cualidades arquitectónicas y los valores históricos del monumento que se habían documentado en profundidad mediante la investigación de archivo y la primera campaña arqueológica.

conocidos con el nombre de "cortinales", se conservaron sin edificar como puede observarse en la fotografía aérea vertical que podemos fechar en la década de los sesenta.

La disposición del edificio perpendicular al sentido de las escorrentías supuso en la práctica la creación de un muro de contención que se comportaba como un embudo por el cual las aguas, en parte canalizadas por el subsuelo, debía atravesar para alcanzar las cotas más bajas. Los constructores romanos fueron conscientes de esta limitación y cimentaron sólidamente el edificio sobre las margas azules, no muy profundas en este lugar, a la vez que crearon un reducido sistema de drenaje mediante atarjeas que, en el lado de poniente, debían proteger al edificio de la acción erosiva de las aguas.

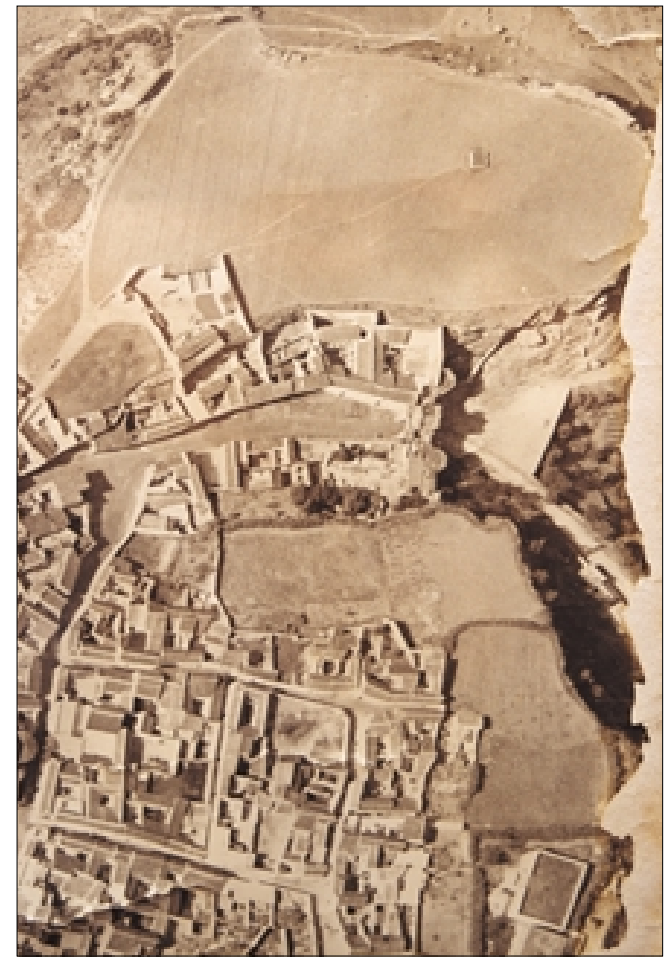

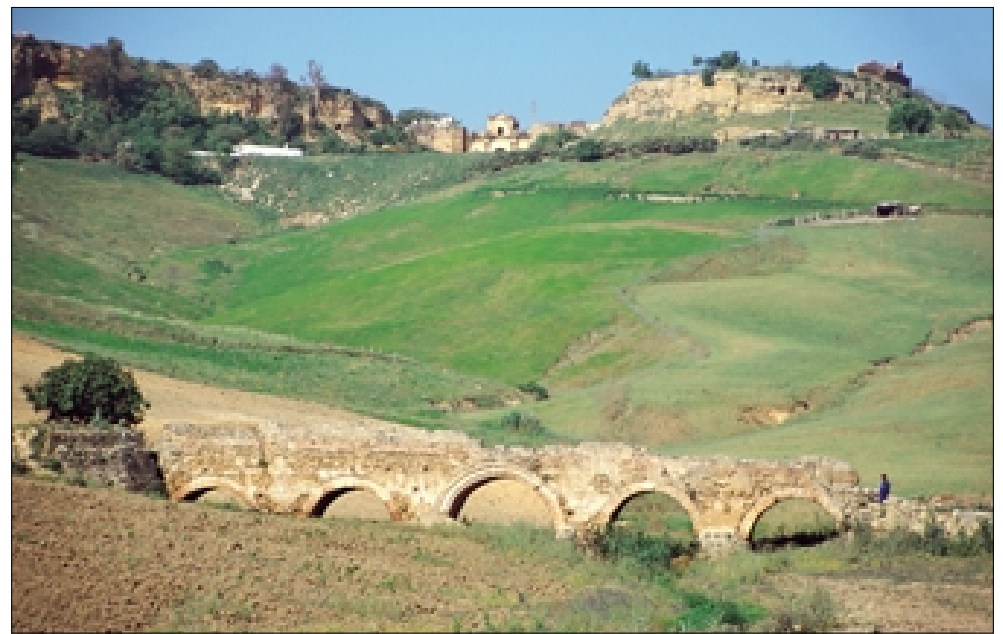

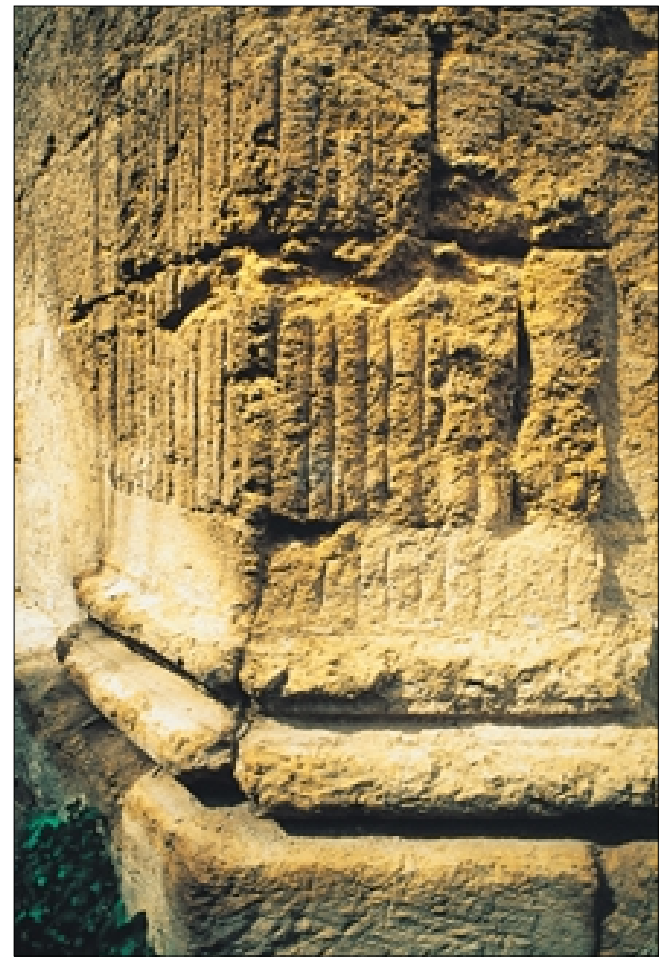

Fig. I. Vista del escarpe del alcor entre el Cortinal Gil de Palma y los restos del Alcázar de la Reina con la Puerta de Córdoba entre ambos y el Puente de los Cinco Vanos abajo.

Fig. 2. Fragmento de la fotografía aérea vertical del sector oriental de Carmona. Oficina Técnica del Ayuntamiento de Carmona. Sin fecha ni autor.

Fig. 3. Efecto de la evaporación del agua que asciende por capilaridad desde el subsuelo sobre el relieve de las pilastras romanas. 


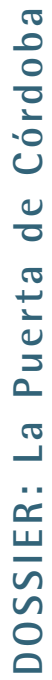

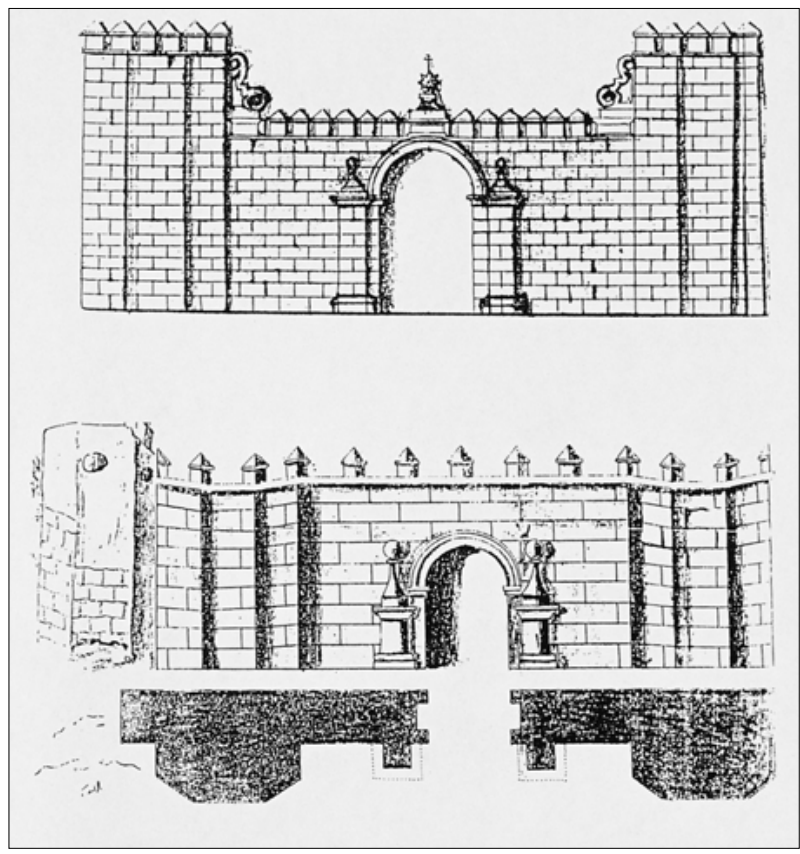

Fig 4. Dibujos de 1775 que nos muestran una puerta completamente almenada.

Fig 5. Detalle del torreón sur con restos de revocos esgrafiados que han sido conservados.
De manera que parece inevitable pensar en un cierto determinismo del medio a la hora de explicar tanto la historia de la Puerta de Córdoba como su estado de conservación, en el que el agua es el principal agente de deterioro, causa de la mayor parte de sus patologías aunque no la única. Las destrucciones, reformas y reconstrucciones que en todas las épocas el hombre ha realizado sobre ella demuestran el valor de su presencia y el vigor de su memoria. Como da a entender la epigrafía más antigua de la propia Puerta ("El tiempo la consumió, el godo la debilitó, Pedro la reedificó, Enrique la castigó, Florez del Carpio/Filipus la reparó siendo corregidor dicho Florez del Carpio. 1609") ' las vicisitudes históricas

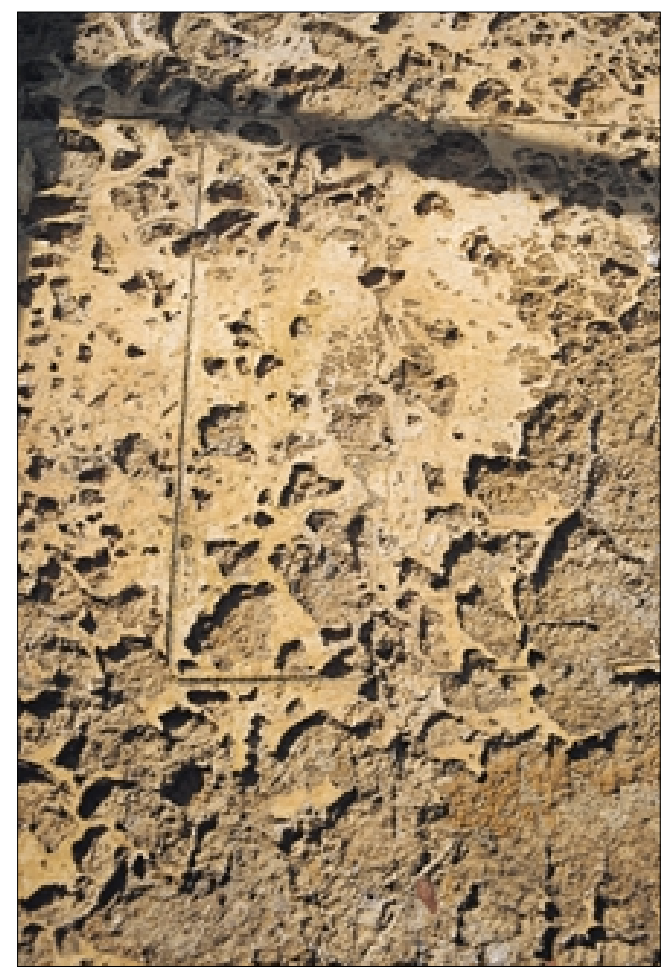

han sido muchas y la acción antrópica decisiva en su actual apariencia.

Cuando el arquitecto natural de Carmona José de Echamorro proyecta a finales del siglo XVIII la última reforma de la Puerta que le confiere su aspecto neoclásico, refuerza el carácter simbólico original acrecentando su altura aunque despojándola definitivamente de su apariencia militar para convertirla en un retablo laico de bienvenida a la ciudad. Un cierto determinismo del medio sólo alterado a partir de los años 70 con la aparición de un vertedero sobre la vaguada que segará por la mitad la visión distante del monumento.

Pero si la ubicación de un monumento en su entorno es una cuestión importante para la comprensión de cualquier arquitectura histórica o contemporánea, en el caso de la Puerta de Córdoba es además esencial para el análisis de las patologías y la valoración de las posibles soluciones técnicas que dependen, a su vez, de las características constructivas y formales.

La Puerta de Córdoba puede describirse como un arco de medio punto flanqueado por dos torreones semioctogonales que enlazan con los dos macizos de alcor mediante sendos lienzos de muralla. Estos lienzos laterales en contacto con el alcor son muros rectos de sillería romana a soga y tizón (de sillares de dimensiones próximas al pie itálico: 53 × 106 cms.), de unos diez metros de altura en la actualidad y casi tres metros de espesor. Las dos torres de flanqueo enmarcan la Puerta propiamente dicha con su actual fachada escenográfica que perdió en gran parte su aspecto militar a finales del siglo XVIII para dotarse de su imagen actual, cuando el interés que poseía ya no era defensivo sino que estaba dado por la topografía y por su misión "estratégicamente" simbólica de acceso a la ciudad.

Las torres semioctogonales se nos muestran con distinta apariencia. En ellas destaca la labra decorativa de pilastras de las aristas, mejor conservadas en la torre sur. En origen, estos torreones estarían decorados con capiteles sobre los que se desarrollaría el entablamento del primer cuerpo según la hipótesis arqueológica. Los remates actuales son de fábrica mixta de mampostería y tapial coronada por dos listeles de ladrillo y merlones de ladrillo terminados en pirámide, que están documentados con anterioridad a la guerra civil por Hernández Díaz y Sancho Corbacho 2.

La fachada entre torreones tiene la altura aproximada de éstos sin las almenas. Se trata de una composición neoclásica de columnas toscanas pareadas, que se remata con falsa balaustrada y con un ático coronado por frontón con jarrones a modo de acróteras. La altura total en el eje vertical alcanza los $17 \mathrm{~m}$. En la decoración de esta fachada, cuyos podios son de sillería superpuesta a la romana -como puede observarse, la fábrica romana permanece en segundo plano a través de algunas pérdidas de la piel neoclásica- destacan dos ventanas y óculos fingidos que centran los intercolumnios, pilastras almo- 
hadilladas remarcando las columnas y el friso decorado con triglifos y metopas. En el ático de esta fachada extramuros existe una lápida que representa el escudo de la ciudad -una estrella de ocho puntascon su pomposo lema: SICUT LUCIFER LUCET IN AURORA ITA IN VANDALO CARMONA.

El color general de los revestimientos de la puerta es un amarillo "calamocha" o "albero" próximo al color natural de la piedra alcoriza, aunque también se han detectado, gracias al estudio de capas cromáticas, restos de enlucido blanco y color almagra en algunas molduras y elementos decorativos de las fachadas neoclásicas cuya escasa profusión no nos ha permitido aventurar una hipótesis decorativa en tres colores que, en cualquier caso no fue la original neoclásica. También existen restos de enlucidos con sillares esgrafiados en el torreón sur, sobre la sillería romana, lo que nos habla de la operación de "uniformización" de color que realiza Echamorro sobre las fábricas preexistentes.

El único vano de acceso existente en la actualidad se conforma con una bóveda de cañón de $6 \mathrm{~m}$. de longitud. En él se localizan, del exterior al interior de la ciudad: la ranura del rastrillo original de la puerta romana, una hornacina que alberga un lienzo del siglo XVIII de la Virgen de Gracia (que ha restaurado el (APH) y, en el lado derecho, una lápida circular con epigrafía en la que se indica que bajo el reinado de Carlos II, se "HIZO LA FABRICA DE ESTA CALZADA REAL" cuando el rey da a Carmona rango de ciudad en 1688.

La fachada que mira a la ciudad es similar a la exterior pero de pilares jónicos y cornisa denticulada, de composición más sencilla y de menor altura ( I5,80 m.) para adaptarse mejor a la escala urbana. Algunas molduras del arquitrabe enlazan con el muro de la casa contigua por el lado sur de la calle Dolores Quintanilla, haciendo evidente su coetaneidad.

\section{Del proyecto ...}

A partir de las solicitudes realizadas por el Ayuntamiento de Carmona y la Asociación Cultural Taracea, la Delegación Provincial de Sevilla de la Consejería de Cultura inició en 1995 los primeros contactos con el Instituto Andaluz de Patrimonio Histórico para la restauración de la Puerta de Córdoba de Carmona. Éste fue perfilando durante los primeros meses del año una estrategia de intervención que se apoyaba en dos ideas fundamentales: por un lado, en una clara diferenciación de las etapas de conocimiento, restauración y valoración del bien inmueble, lo que se traducía en la aportación de un amplio equipo de profesionales dentro de un enfoque integral de la intervención y, por otro, en la coordinación o dirección de las disciplinas vinculadas a cada uno de esos "momentos" del proceso de intervención desde la visión global que la práctica arquitectónica podía ofrecer.
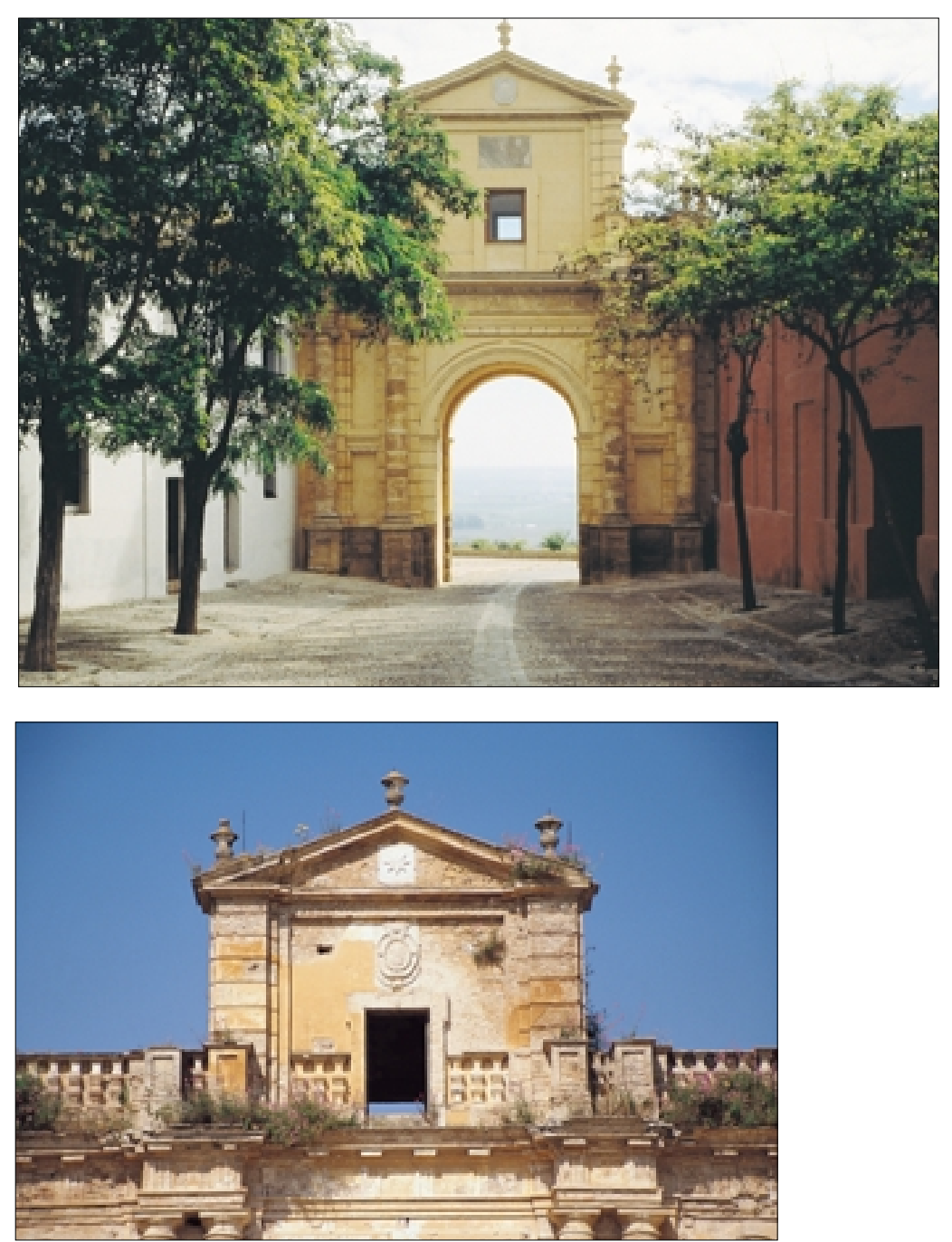

Algunas reflexiones previas permitieron avanzar tanto en la metodología aplicada como en los criterios del proyecto. En las primeras visitas al monumento pudimos comprobar que la Puerta de Córdoba se conservaba virtualmente completa ya que, a pesar de algunas lagunas constructivas, su poderosa simetría permitía una exacta interpretación formal. Descartamos desde el primer momento la recuperación de estados originales de la puerta romana que ya no eran compatibles con el contexto urbano actual en el que las casas avanzan hasta el edificio apropiándose incluso de parte de sus espacios interiores en planta baja ${ }^{3}$. Se trataba de asegurar la integridad material del monumento solucionando sus patologías en la medida de lo posible, para mantener y potenciar sus valores patrimoniales.

El proyecto de restauración se entendía por tanto como un instrumento destinado a hacer más palpables las cualidades arquitectónicas y los valores históricos del monumento que se habían documentado en profundidad mediante la investigación de archivo y la primera campaña arqueológica. Estaba claro entonces para nosotros que el inicio de la obra sería la mejor oportunidad para completar el estudio con metodología arqueológica ya que habían quedado pendientes algunas cuestiones formales y constructi-
Fig 6. Calle Dolores Quintanilla con la Puerta al fondo.

Fig. 7. Vista del estado previo de la fachada oriental del ático con sus evidentes patologías. 


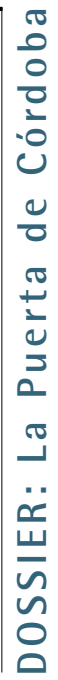

Fig. 8. Plano de estado previo de las fachadas con los indicadores visuales de alteración.

Fig 9. Vista cenital de la bóveda.
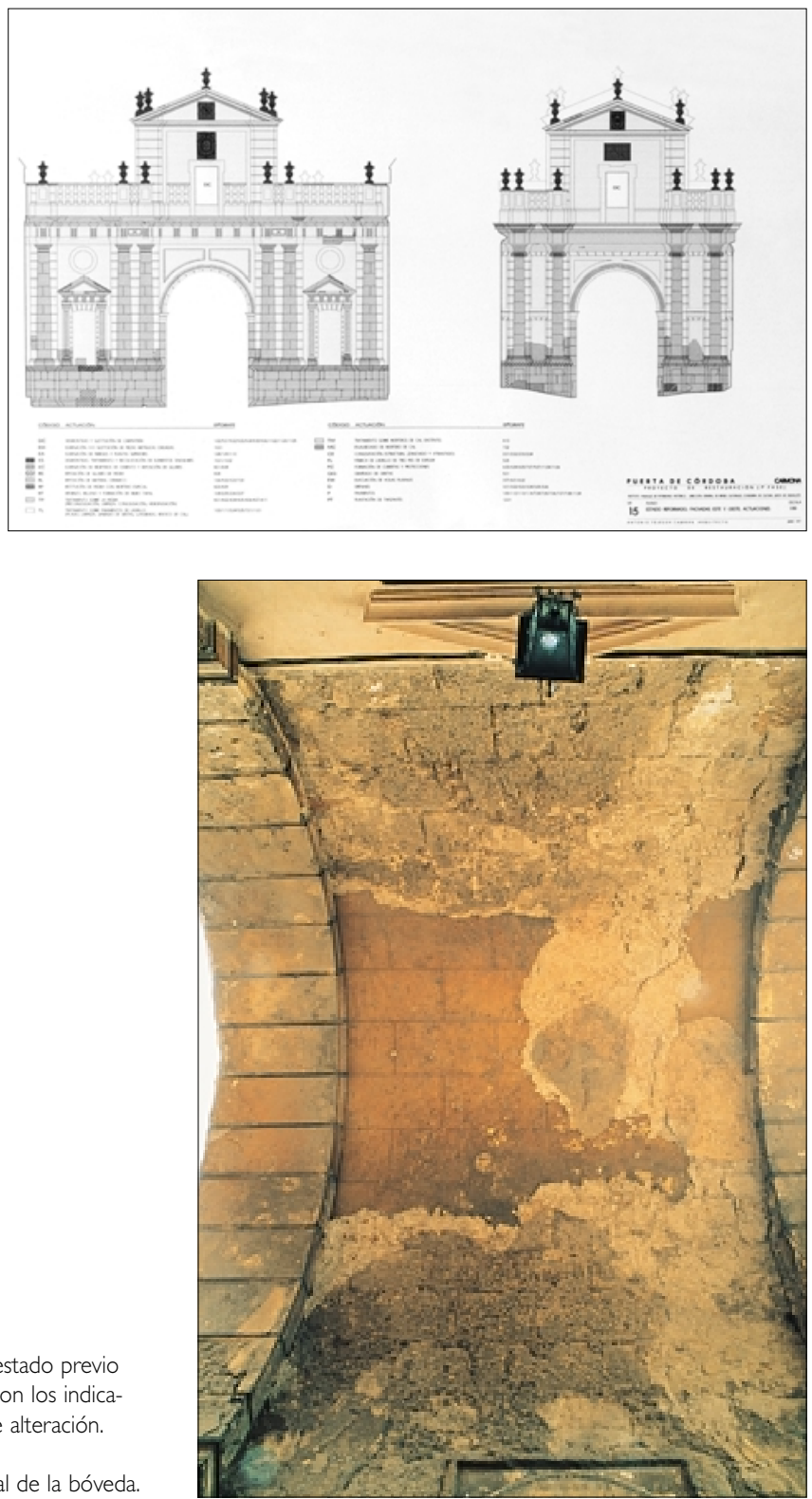

vas de la puerta romana, y así se recogió en la memoria del proyecto ${ }^{4}$.

La intervención se entendió desde el principio con una clara vocación conservativa, es decir, centrada en resolver los aspectos técnicos y científicos que la recuperación de una imagen bien documentada conlleva: limpieza, consolidación estructural, recuperación de revocos, tratamiento de los materiales pétreos y cerámicos, etc.

Sin embargo, estas consideraciones, que vamos a desarrollar más adelante, se enmarcan dentro de una estrategia más amplia. Nuestras primeras iniciativas estaban dirigidas a perfilar una propuesta de intervención integral en tres fases y definir una metodología de trabajo para elaborar los estudios previos destinados a conocer el estado general del monumento, aportar los datos históricos, documentales y materiales necesarios y establecer el alcance de la primera fase de intervención en la Puerta de Córdoba. El necesario en- foque interdisciplinar se extendió a todas las áreas de conocimiento e intervención sobre el bien y su entorno, áreas que podemos resumir en cinco:

I. El perfil biográfico, que es documental (bibliográfico y de archivo) y arqueológico.

2. Los aspectos constructivos y materiales de las fábricas: estado de cimentaciones, estructuras, coberturas, instalaciones, etc.

3. El valor cultural, que es artístico y, a la vez, de identidad colectiva, antropológico.

4. Las nuevas exigencias funcionales según las posibilidades de musealización del monumento y, por último,

5. El valor paisajístico, que refleja el estrecho vínculo del monumento con el lugar y apunta hacia una necesaria intervención en el entorno.

Como consecuencia de este primer análisis establecimos tres fases operativas:

${ }^{\mathrm{a}}$. La restauración del monumento, fase ya concluida, que comprende los estudios previos, la redacción del proyecto y la ejecución de la obra proyectada.

$2^{a}$. La puesta en valor o musealización. Dar a conocer los restos del podio romano y facilitar la visita a la parte alta de la Puerta son los objetivos de esta fase.

3a. Tratamiento del entorno. La visión integral de recuperación de la Puerta de Córdoba que pretendemos desarrollar abarca especialmente al entorno inmediato y distante. La modificación puntual de las obras de pavimentación desarrollas en los últimos años en la explanada delantera y la eliminación del vertedero que se generó en la vaguada contigua condicionando la visión lejana de la puerta son objetivos principales a medio plazo de esta última fase.

Por lo que respecta a la primera fase, sobre la que nos vamos a centrar a partir de este momento, la metodología general seguida en la elaboración del proyecto puede esquematizarse en los siguientes pasos, a menudo simultáneos en el tiempo:

$1^{\circ}$. Investigación de la biografía de la Puerta, relativa a su origen, construcción y ruina, trabajos de refacción, obras de conservación, mantenimiento y reparación. Se articula mediante la investigación documental y la investigación con metodología arqueológica tanto de las estructuras subyacentes como de los paramentos emergentes.

La investigación arqueológica realizada por Reyes Ojeda, Antonio Pérez Paz y Miguel Ángel Tabales es, sin duda, la que ha reportado mayores datos para el conocimiento previo del monumento, sus vicisitudes históricas y sus potencialidades de puesta en valor, al sacar a la luz restos que muestran la relevancia de la puerta romana.

Hay que destacar aquí las aportaciones que la arqueología nos hace sobre las características materia- 


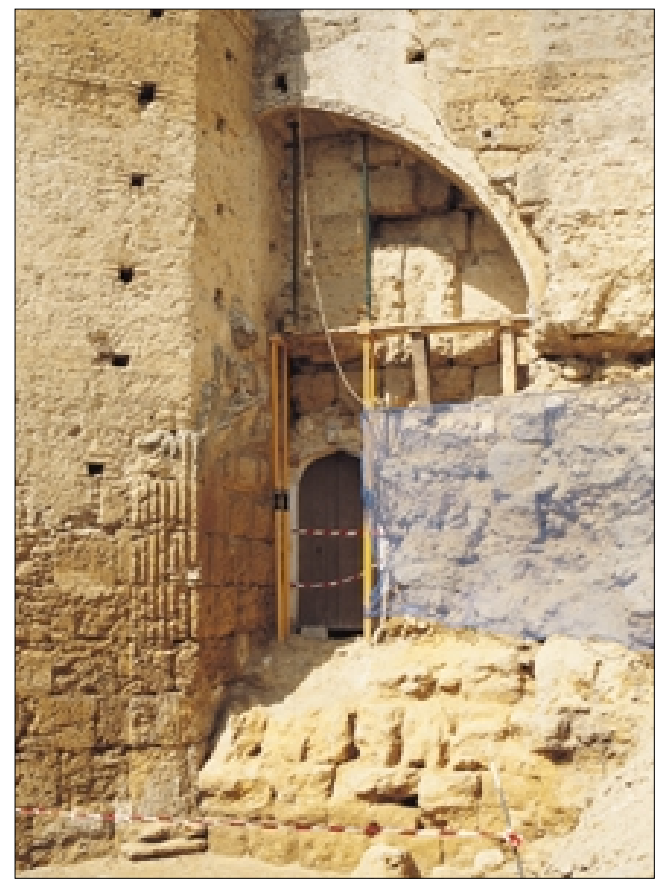

les del edificio y la clasificación de sus paramentos por etapas históricas, dada la utilidad que tienen para calibrar adecuadamente el nivel de intervención óptimo en función del valor histórico-documental de algunas partes en relación con otras más recientes. Resumidamente son dos las aportaciones fundamentales de la investigación histórica:

I. Que la estructura muraria de la Puerta, fechable a principios del siglo I DC consiste en un acceso de triple vano, con dos torres de flanqueo. Los accesos laterales, de menor tamaño, cegados ya en el Bajo Imperio, han permanecido ocultos por las dos casas adosadas a ambos lados de la Puerta que los han incorporado como estancias de almacenaje. Respecto a la puerta romana, se conserva gran parte del alzado correspondiente al primer cuerpo, "forrado" por la fachada neoclásica. Parecidos formales con uno o tres vanos existen, por ejemplo, en: Spello (Puerta de Venus); en Fano (Arco de Augusto) y en Nimes (Puerta de Augusto).

2. El significado propagandístico con que fue concebida, su composición original y la amplitud de la fachada, de $35 \mathrm{~m}$ de longitud, convierten a la Puerta de Córdoba en la puerta romana más monumental de las documentadas en la península ibérica y en una de los pocos edificios que aún conserva su función primigenia, ya sin connotaciones defensivas.

La obra ha permitido profundizar aun más en el conocimiento de la Puerta de Córdoba, y elaborar una hipótesis más ajustada de su estado romano excavando en otras partes del monumento y su entorno que habían quedado sin investigar en la primera campaña.

$2^{\circ}$. Levantamiento planimétrico con un amplio reportaje fotográfico y un exhaustivo apoyo taquimétrico. Incluye el inventario de los elementos decora-

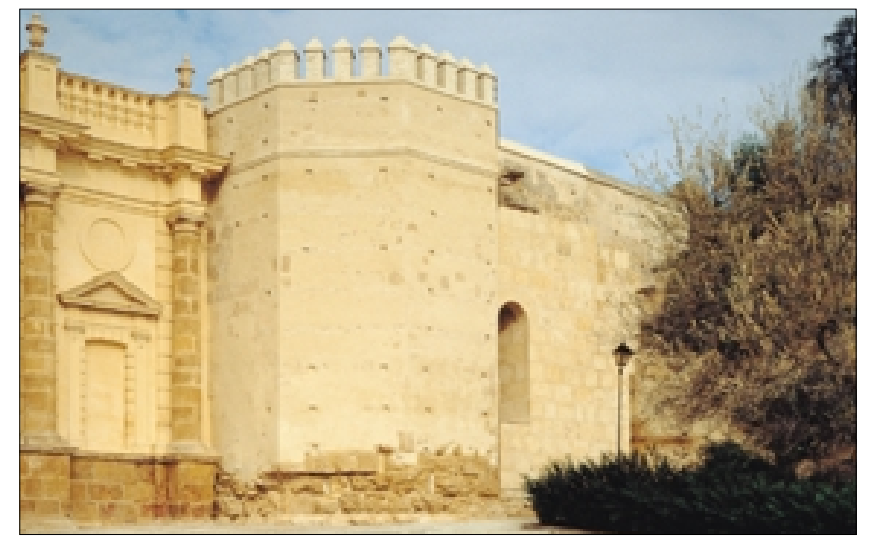

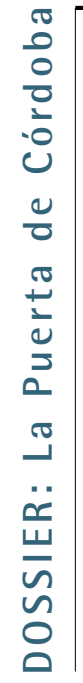

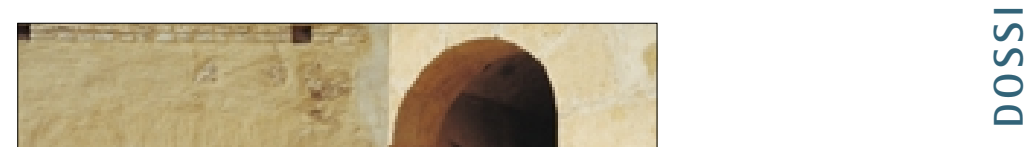

Fig 10. Estado del lienzo norte al inicio de la obra.

Fig I I. Vista final del torreón y el lienzo norte y paterna.

Fig 12. La nueva cortina de piedra del lienzo norte y la poterna. tivos y singulares: lápidas y el material almacenado en el ático de la propia Puerta como jarrones y piezas de cornisas. En nuestra opinión debe realizarse siempre bajo la dirección del arquitecto redactor del proyecto, quien establecerá las escalas y el nivel de detalle de la planimetría básica. La calidad de este levantamiento es fundamental para la bondad del proyecto. También es un instrumento esencial para el estudio arqueológico de los paramentos ${ }^{5}$.

$3^{\circ}$. Inspección ocular detallada del edificio, observando el estado de conservación de los materiales mediante el análisis de los indicadores visuales de alteración 6 y su registro mediante fotografías y croquis detallados que serán después reflejados en los planos correspondientes de patologías.

$4^{\circ}$. Análisis y ensayos de laboratorio. Se realizaron cinco tipos de análisis:

- Determinación de las características mineralógicaspetrográficas de la roca original y alterada con ensayos de difracción y lámina delgada. Se localizaron también las posibles canteras originales sin descartar 

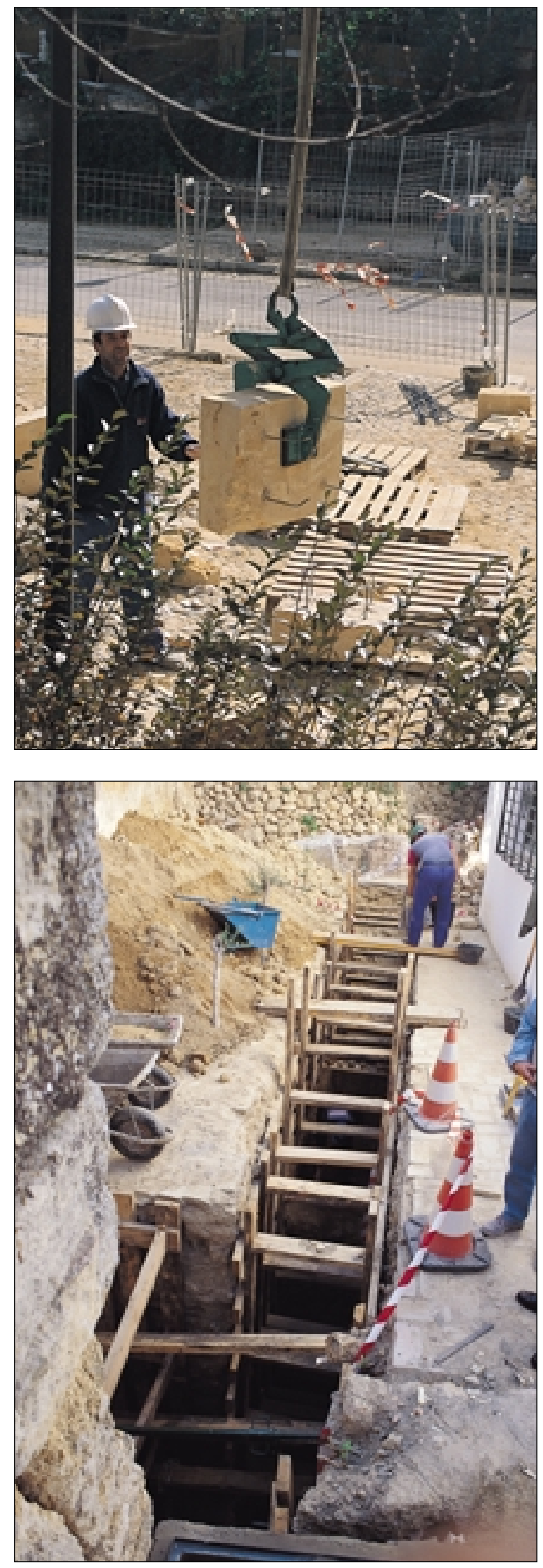

Fio. 14. Zanja entibada para la disposición del drenaje por el lado oeste del lienzo sur. ductos comercializados para la consolidación e hidrofugación. Las características de los tratamientos (producto, composición, materia activa) se recogen en otro lugar de esta publicación

Entre las conclusiones de estos estudios previos destacaremos las siguientes:

A. La piedra utilizada en la Puerta de Córdoba procede de la formación geológica de los Alcores, una calcarenita de color amarillo-anaranjado, con tamaño de grano de arena gruesa y presencia de lamelibranquios de concha fina. La composición mineralógica de la piedra de la puerta es similar a la de las distintas canteras estudiadas, destacando la presencia de yeso como un componente intrínseco al material-aunque una parte pueda proceder de los morteros de unión- y una escasa proporción de minerales de arcilla. Estos componentes, además de la gran porosidad de la piedra -en torno al 34\%-, explicarían el alto grado de alteración de la piedra en los paramentos sometidos a cambios cíclicos en el contenido de humedad.

B. En los morteros utilizados en la obra neoclásica, destaca la presencia de sulfatos (yeso). En los enlucidos exteriores la inexistencia de fragmentos de roca carbonatada indica una mayor selección en el árido.

C. En base a los resultados obtenidos en la medición de la disminución de porosidad, incremento de dureza superficial, absorción por capilaridad, absorción libre de agua, desorción de sales, cristalización de sales y evolución del peso con ciclos de humedad-sequedad, los productos de consolidación e hidrofugación más adecuados para la piedra son, respectivamente, Consolidante $\mathrm{OH}$ y Tegosivin HLI00, que son los que se han aplicado.

$5^{\circ}$. Investigación geotécnica: sobre características del suelo, resistencia y profundidad del nivel freático. Se realizaron ensayos de identificación de los estratos con dos sondeos. A un metro de profundidad, el suelo es de transición a marga con una alta resistencia a compresión simple, entre 2,5 y $3,25 \mathrm{kp} / \mathrm{cm}^{2}$.

$6^{\circ}$. Propuesta de intervención, redacción del documento de proyecto y realización simultánea de una maqueta de la puerta y su entorno, que se encuentra depositada en la actualidad en el Museo de la Ciudad.

que buena parte de los sillares procedieran de construcciones preexistentes y del desmonte del alcor para la edificación de la puerta romana.

- Ensayos químicos para determinar los componentes de la roca original y la roca alterada.

- Ensayos sobre características físico-mecánicas de la roca original y la alterada.

- Caracterización de los morteros y microestratigrafía de los enlucidos.

- También se efectuaron experiencias de alteración acelerada, sobre probetas de piedra extraídas del monumento, con el fin de comprobar su comportamiento después de ser tratadas con cuatro pro- $7^{\circ}$. Otros estudios no se consideraron necesarios por no existir factores ambientales contaminantes ni se realizaron análisis biológicos. Los estudios previos sí se completaron en los dos primeros meses de obra, una vez colocados los andamios, con el estudio de las capas de color originales, lo que técnicamente se denomina "estudio de correspondencia de capas pictóricas". Este aspecto era especialmente importante para nosotros, coherente con el carácter general de la intervención que hemos calificado como de "simple conservación", ya que la imagencolor de la Puerta de Córdoba debía ser "reconocida" tras la intervención. 


\section{... a la obra}

Estructuralmente la Puerta de Córdoba no presentaba patologías de gravedad que pusieran en riesgo su integridad, excepto en el lienzo norte. Las grietas observadas en el vano central junto al arco oriental podían tener su origen tanto en una escasa trabazón de los paños de fachada respecto del relleno de la bóveda y de los paños de fachada del ático respecto de sus muros laterales de cerramiento, como en las vibraciones producidas por el paso de vehículos a través del vano central. Estas grietas podían estar más o menos estabilizadas teniendo en cuenta que la cimentación descansa directamente sobre un terreno de transición a margas de gran capacidad resistente. A pesar de ello se recomendó al Ayuntamiento de Carmona la restricción del tráfico pesado bajo la Puerta como medida preventiva.

Otros problemas de carácter estructural se producían en los lienzos norte y sur, mucho más graves en el lado norte debido a la pérdida de la cortina muraria de sillares (opus quadratum) que había dejado al descubierto el emplekton romano y en precaria estabilidad los recrecidos de tapial que se superponen. Desconocemos el momento en que se dispuso el arco de descarga de traza apuntada y el relleno ataluzado que le acompañaba aunque nos hablan de problemas de estabilidad desde muy antiguo que no quedaron resueltos, dadas las grietas y pérdidas que presentaban ambos. Todo ello se agravaba, aun más, por la pérdida de masa y socava del alcor en las proximidades del lienzo, lo que en la práctica se traducía en una pérdida recíproca de sustentación 7 .

Si en el lienzo sur la construcción de un nuevo muro de ladrillo entre el extremo del lienzo y el alcor también, nos ha permitido fijar una parte del monumento sometida a graves erosiones con una solución similar a la que existía en este lugar, por su parte, la consolidación del lienzo norte mediante la recuperación de la cortina de piedra exterior conlleva decisiones más complejas. Al pésimo estado estructural de esta parte del monumento se sumaba el hecho de que ofrecía una lectura distorsionada sobre el modo en que se producía el contacto con el alcor. El nulo valor constructivo y formal de las reparaciones realizadas en el pasado con la aparición de arcos de descarga, taludes y fragmentos reutilizados del propio lienzo, y la acelerada pérdida de los restos romanos del muro defensivo que habíamos constatado, nos condujeron a la recuperación de la estructura original del lienzo y de la poterna que se disponía en contacto con el torreón. La posición y tamaño de la misma habían sido documentadas por los arqueólogos cuyo informe ofrecía certezas razonables y suficientes para acometer tal recuperación.

El sistema constructivo utilizado se asemeja al original romano aunque con algunas variaciones: tongadas de sillares que se van rellenando con un hormigón de matriz caliza. Los sillares ofrecen dimensiones similares a los del lienzo sur, aunque de menor espesor dadas las limitaciones presupuesta-

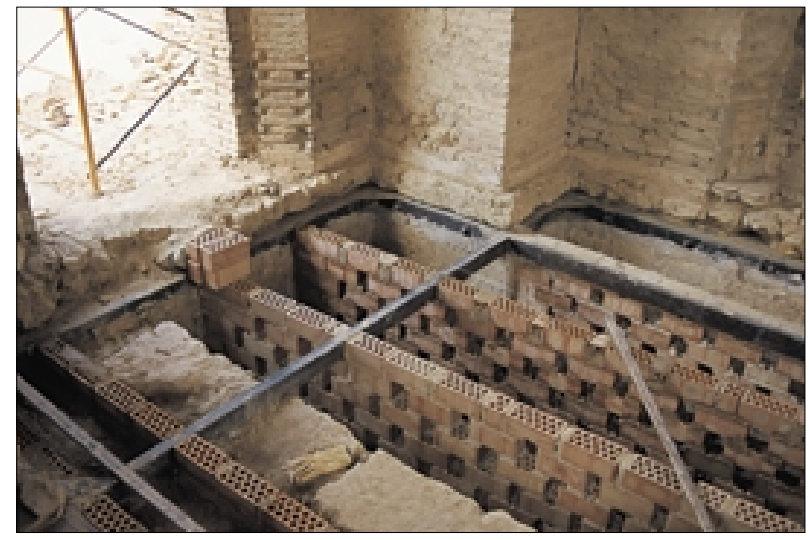

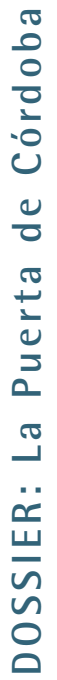
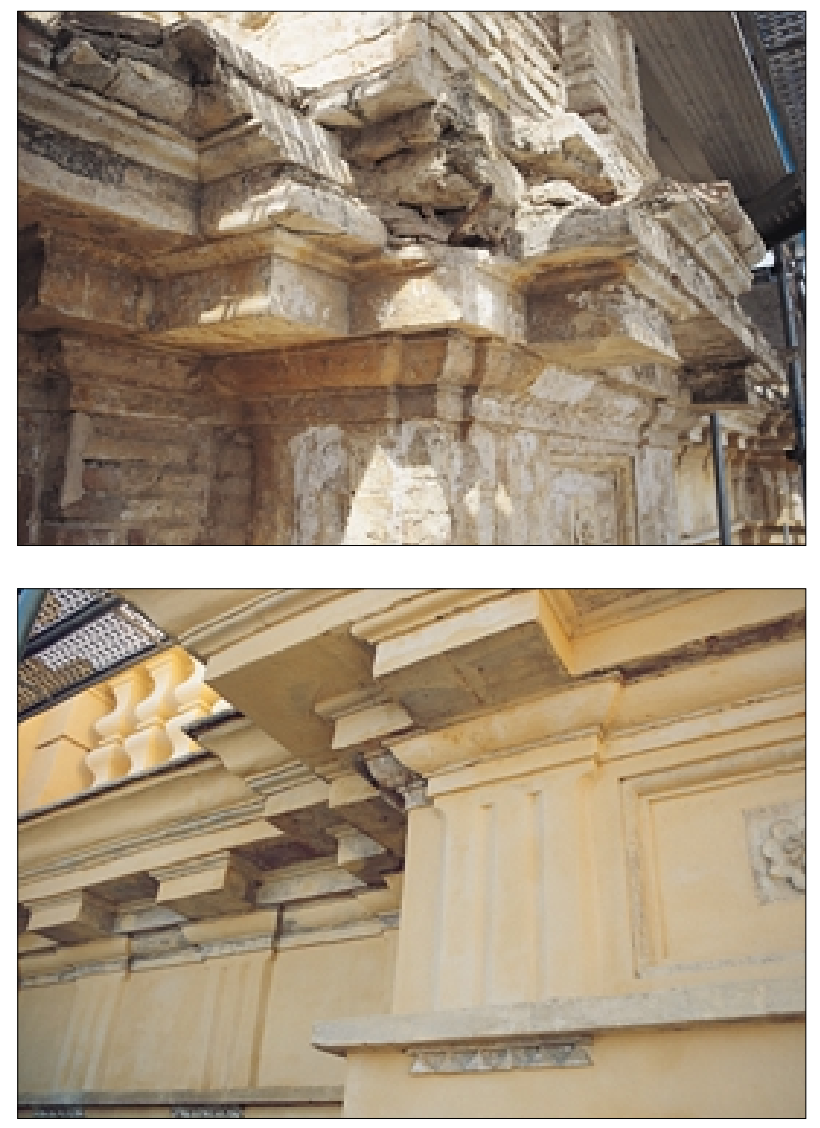

rias de puesta en obra. A cada uno de ellos se le introdujeron cuatro pernos de acero inoxidable para mejorar la adherencia al relleno y se trataron por sus caras no visibles con resina acrílica para evitar la migración de sales a la cara externa.

Otras operaciones estructurales han sido el atirantado y zunchado del ático, a nivel de la cubierta y del suelo, respectivamente. En cubierta se utilizaron tirantes de acero de alta resistencia postensados y embutidos en fundas rígidas de plástico rellenas con lechada de cemento. En el suelo del ático, se dispuso un atirantado de perfiles de acero en $\mathrm{C}$, conformando dos rectángulos soldados y anclados a los muros con pernos recibidos con resina epoxi. El vaciado arqueológico del trasdós de la bóveda permitió sustituir el relleno de tierra por un tabicado de citara sobre el que se colocaron rasillones para recibir la solería final.
Fig. 15. Atirantado a nivel del suelo del ático.

Fig. 16 y 17. Detalle de una cornisa de la fachada oeste antes $y$ después de la intervención. 


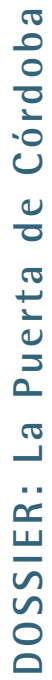

Fig. 18 y 19. Aspecto parcial de las cubiertas antes y después de la intervención.
Consolidaciones menores fueron el cosido de las grietas observadas en los muros de piedra y ladrillo, tanto en la bóveda del vano central como en las fachadas, mediante llaves de acero inoxidable e inyección de resina epoxi y sellado de grietas y fisuras en la piedra con mortero de Primal. Para la ejecución de este lienzo ha sido muy importante localizar una cantera en uso en Alcalá de Guadaira, de donde extraer la piedra alcoriza de naturaleza similar a la existente en el monumento.

En la obra realizada destaca, por su dificultad, la actuación destinada a reducir el efecto de las humedades de infiltración provocadas tanto por la singular yuxtaposición del edificio con el alcor y los rellenos que históricamente se han consolidado en el lado occidental, como por el adosamiento de las viviendas contiguas.

La disposición de la Puerta de Córdoba entre dos alcores como obstáculo a la escorrentía natural de la vaguada facilita la transmisión de humedades de infiltración a las fábricas, con un desarrollo vertical mayor en el lienzo sur (sobre los $7 \mathrm{~m}$ respecto de la
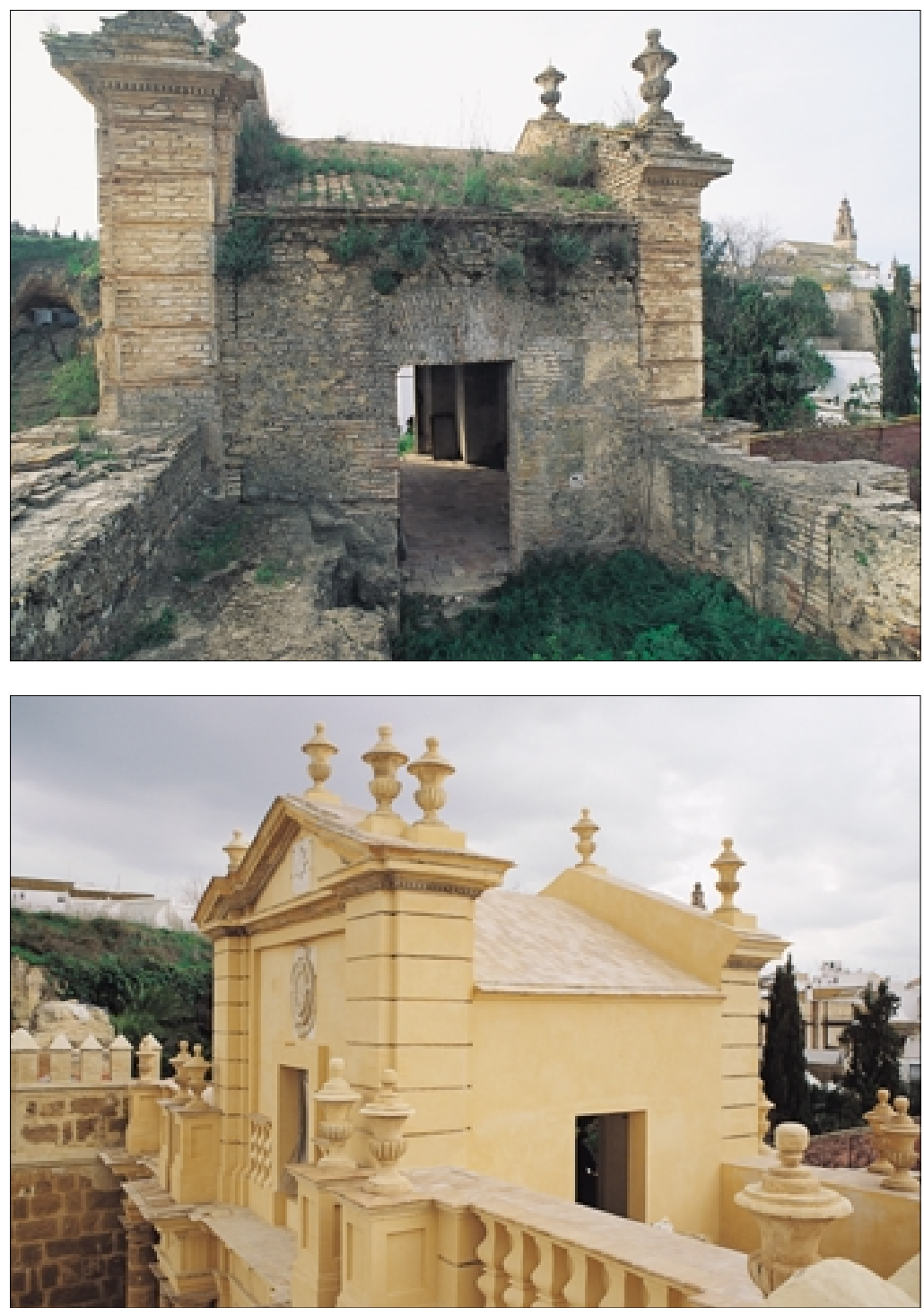

cota del suelo) que en el norte (sobre los $2 \mathrm{~m}$ ). Al efecto disgregador del agua especialmente sobre los paramentos de calcarenita más antiguos se suman los de las humedades de capilaridad. La acción directa del agua de lluvia es también especialmente grave por la pérdida total de función impermeabilizadora de los pavimentos de las cubiertas y de los remates de los petos y las almenas.

Con la disposición de los drenajes pretendemos reducir el efecto de las humedades de infiltración procedentes del relleno y del alcor del trasdós de los lienzos y las torres que flanquean la Puerta. Se tantearon diversas soluciones para la eliminación de las humedades de capilaridad optándose finalmente, por lo que afecta a esta primera fase de obra, por no inyectar productos mineralizadores para crear barreras químicas, ni otras soluciones ya contrastadas que sí pueden funcionar en fábricas homogéneas y con espesores más reducidos. La profundidad de los drenajes en el lado de poniente exigió realizar las zanjas por bataches y colocar entibaciones de madera para superar los cinco metros de profundidad. Estos drenajes se conectaron a la red pública de saneamiento que discurre por debajo de la Puerta.

Patologías no menos importantes son las que afectaban a los revestimientos de la fábrica de ladrillo de la puerta neoclásica. La aparición masiva de plantas superiores y la oxidación de vástagos y refuerzos metálicos aceleraron la extensión y la gravedad de las pérdidas de elementos decorativos y molduraciones, la caída de fragmentos de las cornisas y el deterioro de la fábrica de ladrillo donde había quedado más expuesta.

En los elementos decorativos, molduras y cornisas se procedió tanto a la eliminación de musgos, líquenes y algas con biocidas como al saneado y rejuntado de las llagas y juntas con mortero de cal en los paramentos de ladrillo. Los paramentos neoclásicos se revistieron a continuación con mortero de cal y arena rubia y se revocaron con un estuquillo de marmolina, cal y pigmentos naturales que le dieron el color deseado. Este procedimiento (que difiere del original, simple pintura sobre el mortero) facilitará el mantenimiento de las fachadas. Los morteros existentes que se encontraban bien adheridos al soporte se han consolidado por su valor documental. Los elementos decorativos como los jarrones y algunas grandes piezas de las cornisas se han fijado mediante anclajes y vástagos de acero inoxidable recibidos con resina epoxi. Para la completa restauración de las cornisas se realizó un inventario de todos los tipos de ladrillo existentes, se evaluaron las pérdidas y se encargaron las piezas necesarias de cada tipo.

Como ya hemos señalado, el estado de la piedra era muy variable según fuera su función estructural u ornamental, su orientación respecto del sol y la lluvia y su altura. Las actuaciones sobre la PIEDRA fueron: limpieza y tratamientos de consolidación e hidrofugación con los productos seleccionados en laborato- 


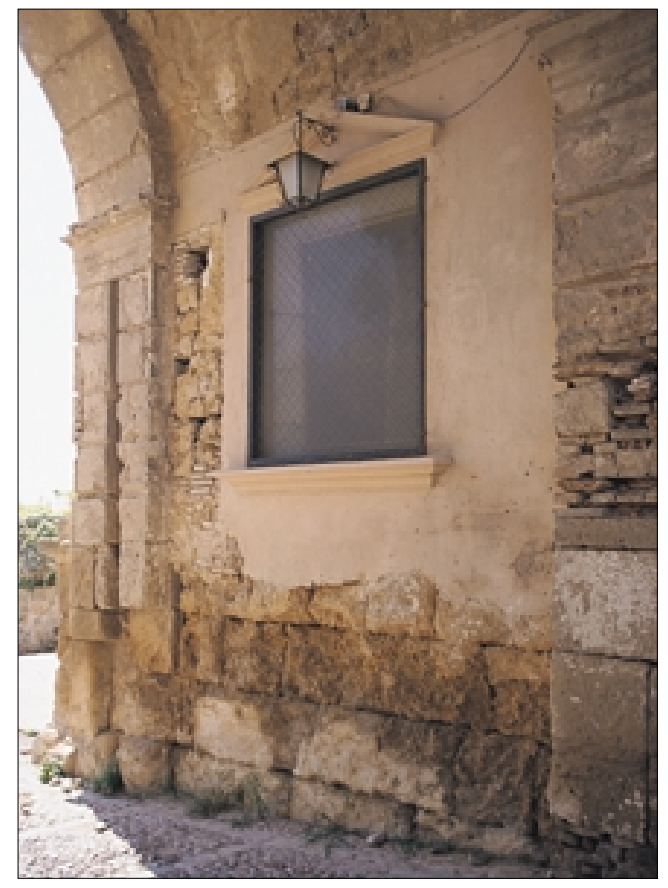

rio y tratamiento de las fisuras y restitución del material perdido a base de morteros especiales con Primal.

Las cubiertas tenían problemas de filtraciones y pérdidas de juntas que afectaban de humedad a las bóvedas y los macizos inferiores. El problema más grave era la permeabilidad de los adarves, tanto sobre las torres como sobre los laterales del vano central. El desarrollo de plantas superiores era extraordinario y el precario sistema de evacuación de las aguas a través de mechinales no cumplía su labor. Por ello, se procedió a eliminar los árboles y las plantas superiores con herbicidas y se impermeabilizaron las cubiertas, los adarves y las albardillas de petos y almenas con pinturas al clorocaucho sobre mallas de fibra de vidrio. La evacuación de las aguas pluviales por los mechinales existentes se facilita ahora con las pendientes adecuadas. Para la reconstrucción de los tapiales se utilizaron hormigones similares a los del tapial, utilizando una matriz caliza, fragmentos de piedra y cascotes de ladrillo. Se dispusieron encofrados de madera y se hormigonó por tongadas de manera similar a la técnica original.

Otros trabajos ejecutados en la Puerta de Córdoba han consistido en disponer una nueva instalación eléctrica sin cables por las fachadas del monumento. Se han dispuesto puntos de luz y tomas de corriente en el ático en previsión del uso futuro y para facilitar el mantenimiento. También se han dispuesto nuevas carpinterías de madera de iroko en los vanos del ático y se ha protegido el cuadro de la Virgen de Gracia restaurado con un vidrio Securit de $12 \mathrm{~mm}$. puntualmente perforado tanto en la parte inferior como en la superior para permitir cierta ventilación de la hornacina en la que se ubica.

Pero la obra también ha servido para completar el registro arqueológico, cuya utilidad para la arquitectura es obvia cuando se persigue el mismo objetivo, la con-

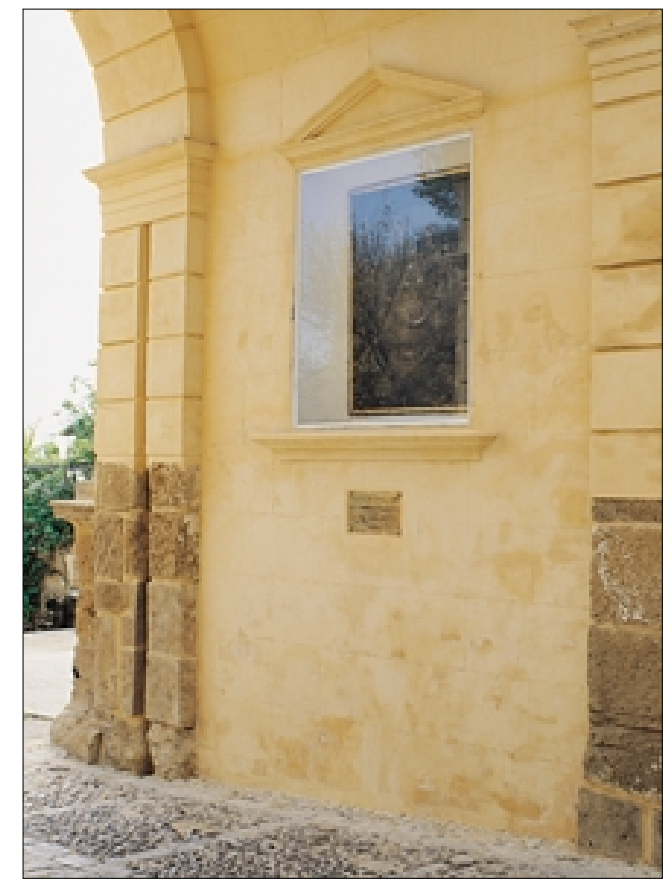

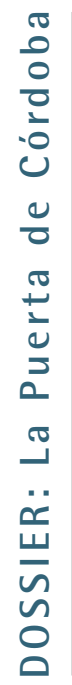

servación/restauración del monumento (en la obra nueva, especialmente en las llamadas urgencias o "urbanas", la relación entre arquitectos y arqueólogos no es comparable o, sencillamente, no existe). Creemos que el sistema de registro debe caracterizarse por su concreción e inmediatez ya que, de otra forma, los datos de la investigación no trascienden a la obra pues sólo se elaboran para su publicación. La utilidad del registro reside más en la capacidad de ofrecer los datos concretos en un informe preliminar que en esperar a la memoria final de la excavación; es preferible un breve informe que contenga una planimetría básica de la evolución del edificio en planta y alzado, incluso a mano alzada, y transmitir las alternativas y las dudas de interpretación, no sólo las certezas.

Desde nuestra experiencia creemos que el arqueólogo debe participar en todas las fases del proceso de restauración:

- En los estudios previos de carácter histórico, los análisis de paramentos y enlucidos, incluso en los estudios de correspondencias de capas pictóricas, para la correcta interpretación de la evolución del monumento. No se debe entender el edificio como fragmentado en estructuras subterráneas y emergentes.

- En la redacción del proyecto arquitectónico, aportando datos específicos de las fábricas, aparejos y técnicas constructivas, así como la valoración y los criterios de puesta en valor.

- En la ejecución de la obra, tanto más si mayor es la antigüedad del edificio y el grado de intervenciones que ha soportado. Cualquier actuación en el terreno debe tener un seguimiento arqueológico.

- En la difusión de los resultados, aportando lecturas complementarias.

Para la puesta en valor del monumento restaurado hemos iniciamos en diciembre de 1999 la segunda fa-
Fig. 20 y 21. Hornacina de la Virgen de Gracia, patrona de Carmona, antes y después de la intervención. 


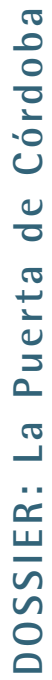

Figuras 22 y 23. Detalle de la fachada oriental antes y después de la intervención.

Figura 24. Vista de la vega del río Corbones desde el adarve norte.
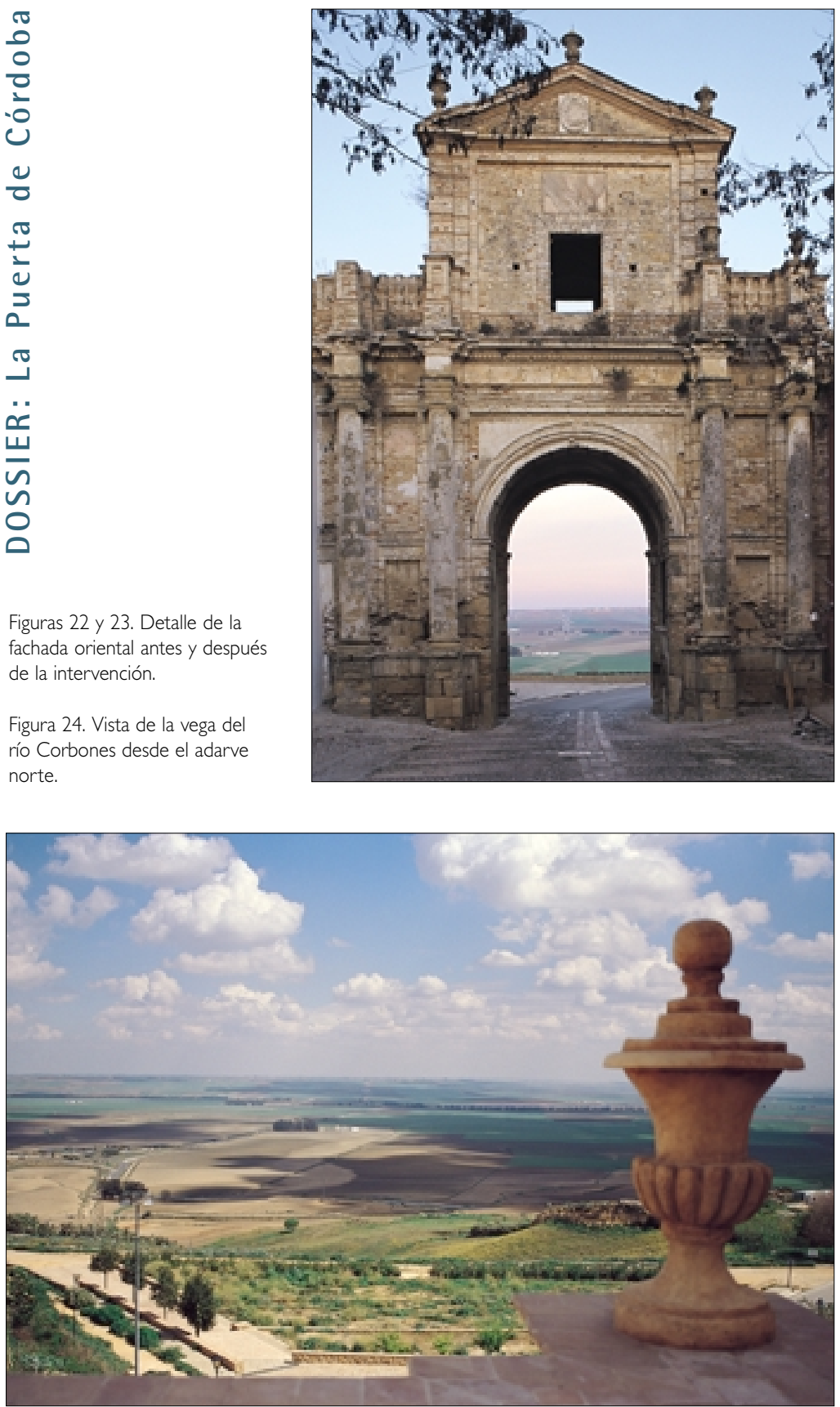

Notas

I. Sólo pudimos transcribir el texto original cuando se colocaron los andamios de obra, ya que en las últimas líneas se superponen letras y la propia fecha. Traducción libre de "TMP CONSVMIT GOTHVS DINVIT - PETRVS REEDIFICAT - ENRICVS PVNIVIT FLOREZ DEL CARPIO REPARAVIT - SIENDO CORREGIDOR DICHO FLOREZ DE CARPIO I609"

2. HERNÁNDEZ DÍAZ, J. SANCHO CORBACHO, A. COLLANTES DE TERÁN. F. Catálogo Arqueológico y Artístico de la Provincia de Sevilla. Tomo II (C). Excma. Diputación Provincial de Sevilla. Sevilla 1943. Fig. 443 y 444.

3. A finales del siglo XVIII la calle Dolores Quintanilla ya presentaba su configuración actual aunque el arquitecto José Echamorro potencia la simetría sobre la Puerta regularizando la fachada del lado meridional.

4. Veáse TEJEDOR CABRERA, A. "El proyecto de restauración de la Puerta de Córdoba en Carmona. Metodologías y propuestas". En PH Boletín del IAPH. 22. Marzo 1998. Pp. 62 y 63.

5. Los resultados del trabajo de campo fueron trasladados a un

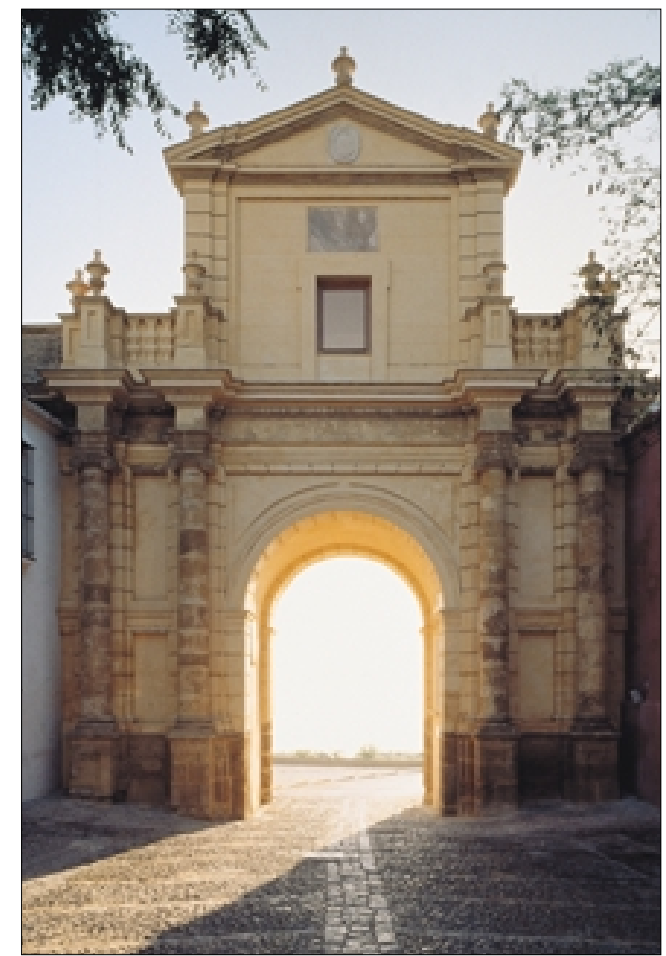

se de la intervención con el proyecto de un centro de interpretación que, como ya hemos dicho, está fundamentalmente destinado a incorporar los restos del podio romano excavado en la primera campaña arqueológica y facilitar el acceso al ático dentro de una visita selectiva al monumento que complemente la oferta patrimonial y turística de la ciudad.

Las posibilidades de desarrollo de estos objetivos están siendo estudiadas en coordinación con el Ayuntamiento y la propiedad de la casa de calle Dolores Quintanilla, y pasan por la incorporación al uso público de los espacios asociados al vano lateral sur de la Puerta, que en la actualidad están anexionados a dicha casa. Esta intervención de puesta en valor será el complemento adecuado de la restauración realizada que sólo se justifica con la transmisión de sus contenidos al ciudadano mediante una labor divulgativa en distintos niveles y foros.

programa informático de dibujo asistido que permitía recoger la información en tres dimensiones. Se buscó, especialmente, la definición precisa de los planos de proyección de los alzados y el apoyo exhaustivo de los lienzos laterales de la puerta, tanto por el lado de levante como por el poniente, es decir, representando el contacto del monumento con el alcor y con las estructuras edilicias adosadas a él. Este trabajo nos permitió, además, comprobar la geometría y simetría de la composición neoclásica y facilitó la toma de datos in situ con métodos manuales tradicionales de cinta métrica, lápiz y papel que completaban la información obtenida con el taquímetro. (si no existen levantamientos completos siempre es recomendable la utilización de técnicas fotogramétricas, especialmente cuando la intervención supere los 35 ó 40 millones de presupuesto de ejecución material ya que supone menos de un $5 \%$ del coste de la obra).

6. Según nuestra interpretación de la clasificación de alteraciones de Manuel Alcalde y Rosario Villegas que se puede consultar en varios números de $\mathrm{PH}$.

7. Véase TEJEDOR CABRERA, A. Opus cit. P. 59. Fotografías 4, 5 y 6 